\title{
Disorders of sex development: timing of diagnosis and management in a single large tertiary center
}

\author{
E Kohva ${ }^{1,2}$, P J Miettinen', S Taskinen ${ }^{1,3}$, M Hero', A Tarkkanen ${ }^{1,2}$ and T Raivio ${ }^{1,2}$ \\ ${ }^{1}$ Children's Hospital, Pediatric Research Center, University of Helsinki and Helsinki University Hospital, Helsinki, Finland \\ ${ }^{2}$ Faculty of Medicine, Department of Physiology, University of Helsinki, Helsinki, Finland \\ ${ }^{3}$ Department of Pediatric Surgery, Children's Hospital, University of Helsinki and Helsinki University Hospital, Helsinki, Finland \\ Correspondence should be addressed to T Raivio: taneli.raivio@helsinki.fi
}

\begin{abstract}
Background: We describe the phenotypic spectrum and timing of diagnosis and management in a large series of patients with disorders of sexual development (DSD) treated in a single pediatric tertiary center.

Methods: DSD patients who had visited our tertiary center during the survey period (between 2004 and 2014) were identified based on an ICD-10 inquiry, and their phenotypic and molecular genetic findings were recorded from patient charts. Results: Among the 550 DSD patients, $53.3 \%$ had $46, X Y$ DSD; $37.1 \%$ had sex chromosome DSD and $9.6 \%$ had $46, X X$ DSD. The most common diagnoses were Turner syndrome $(19.8 \%$, diagnosed at the mean age of $4.7 \pm 5.5$ years), Klinefelter syndrome $(14.5 \%, 6.8 \pm 6.2$ years) and bilateral cryptorchidism (23.1\%). Very few patients with $46, X Y$ DSD $(7 \%)$ or $46, X X$ DSD $(21 \%)$ had molecular genetic diagnosis. The yearly rate of DSD diagnoses remained stable over the survey period. After the release of the Nordic consensus on the management of undescended testes, the age at surgery for bilateral cryptorchidism declined significantly $(P<0.001)$.

Conclusions: Our results show that (i) Turner syndrome and Klinefelter syndrome, the most frequent single DSD diagnoses, are still diagnosed relatively late; (ii) a temporal shift was observed in the management of bilateral cryptorchidism, which may favorably influence patients' adulthood semen quality and (iii) next-generation sequencing methods are not fully employed in the diagnostics of DSD patients.
\end{abstract}

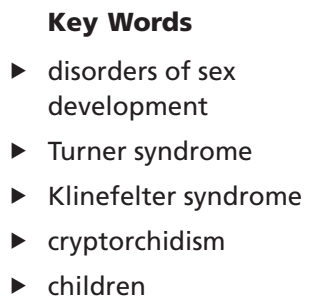

Endocrine Connections (2018) 7, 595-603

\section{Background}

Disorders of sexual development (DSD) are congenital conditions in which the chromosomal, anatomic or gonadal sex development is atypical (1). Today, DSD is classified into three major categories by the patient's karyotype: sex chromosome DSD, 46,XY DSD and 46,XX DSD (1). The phenotypic spectrum of DSD is wide, and it can manifest as a complete sex reversal, a solitary genital abnormality or it can be a part of a syndrome affecting other organ systems (2). The etiology of DSD is multifaceted and can be caused by genetic and environmental factors; especially, hypospadias and undescended testes have been linked to the actions of environmental agents (3). A family history with genital abnormalities, delayed puberty, infertility, stillbirths or multiple miscarriages should lower the threshold for molecular genetic investigations (4). A newborn with ambiguous genitalia requires evaluation by a multidisciplinary team that aims to determine the sex of rearing, and eventually designs a long-term management plan in close co-operation with the patient and the family (1). It is generally agreed that

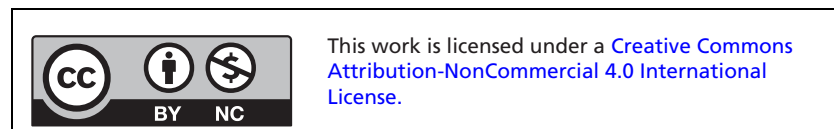


timely diagnosis and management are important as they potentially prevent adverse health outcomes and improve long-term, health-related quality of life $(5,6,7,8,9,10)$.

There are currently only a handful of systematic and comprehensive reports on the etiology and management of DSD patients $(11,12,13,14,15,16,17)$. At the same time, there is a vivid ongoing global debate on the treatment policies of these patients $(4,14,18,19,20)$. The first step toward evidence-based, optimal care of this patient group would be to describe the current status of diagnostics and management in pediatric tertiary centers. In this study, we describe the phenotypic spectrum and molecular genetic findings of DSD patients treated at the Helsinki University Hospital between 2004 and 2014, with special attention on the timing of diagnosis and management of the most prevalent DSDs.

\section{Patients and methods}

We performed an ICD-10 code-based inquiry covering the years from 2004 to 2014 to the electronic patient information system of the Helsinki University Hospital, the tertiary center of the Helsinki metropolitan area (catchment area 1.2 million people in 2014, 0.3 million of which were children and adolescents $0-20$ years old (21)) also nationally responsible for treating severe and rare illnesses. We included diagnoses describing phenotypes with deviations in chromosomal, gonadal or phenotypic sexual development. To examine the relation of minor anatomic deviations to actual DSDs, we accepted a wide range of diagnoses (i.e. distal hypospadias and/or unilateral cryptorchidism) in the search (Table 1). We identified altogether 3206 patients who had visited the Pediatric, Pediatric Endocrine and/or Pediatric Surgical Clinics for the evaluation of treatment of DSD or a minor anatomic deviation. The selection of these outpatient clinics was based on their clinical practice: every DSD patient visits either pediatrician, pediatric endocrinologist or pediatric surgeon. Data from other departments (i.e. genetics) were utilized, if available. In the more thorough examination, we included patients with ICD-10 diagnoses describing DSD phenotypes as defined by the LWPES/ESPE consensus group in 2006 (1), and hence, also accepted bilateral cryptorchidism and penoscrotal or perineal hypospadias. We reviewed the electronic patient records of these patients $(n=885)$ for clinical features, karyotype and molecular genetics to verify their diagnoses and record their family anamnesis (Fig. 1). The date of diagnosis was defined as the first remark by a pediatric endocrinologist

$$
\text { http://www.endocrineconnections.org }
$$

or a pediatric surgeon in the patient data system on either clinical or molecular genetic DSD diagnosis. Patients over 20 years old and patients with unilateral cryptorchidism, distal hypospadias, epispadias, chordee, cloaca, congenital rectovaginal fistula, imperforate hymen, bifid clitoris or fusion of labia were excluded from the analyses. Boys with congenital adrenal hyperplasia (CAH) were not considered DSD patients since no DSD phenotype was present.

We paid special attention to patients who had either Turner syndrome (TS) or Klinefelter syndrome (KS). The ICD-10 inquiry returned originally 134 patients with TS diagnosis. Manual verification of the patient records revealed, however, that 25 of them did not meet the definition for TS (9) and therefore 109 TS patients were included in the analyses. Similarly, we excluded 5 of the $85 \mathrm{KS}$ patients identified by the original ICD-10 inquiry, as they were found not to meet the criteria for KS (22). The age at diagnosis was available for 90\% $(n=98)$ of TS patients and $85 \%(n=68) \mathrm{KS}$ patients. Approximately half of TS (51\%) and KS (55\%) patients were diagnosed during the study period.

To study the management of bilateral cryptorchidism, we evaluated all 46,XY DSD patients retrieved by the ICD-10 search (Table 1). The patient records of boys referred for isolated bilateral cryptorchidism or a more complex phenotype accompanied by bilaterally undescended testes were reviewed. The age at bilateral orchiopexy or the first of the two unilateral orchiopexies was recorded for each boy and used in subsequent analyses.

\section{Statistical analyses}

Correlations between variables were assessed with Spearman rank correlation analysis. Mann-Whitney $U$ test and chi-square test were used to compare the ages of boys with bilateral cryptorchidism operated between 2004 and 2007 or 2008 and 2014. The data in the text are presented with a mean \pm s.D. and the data in the tables as median (range) unless otherwise stated. $P<0.05$ was accepted to indicate statistical significance.

\section{Results}

\section{Phenotypic spectrum of DSD patients and timing} of diagnosis

We identified 3206 patients who were evaluated for one or multiple ICD-10 diagnosis of interest in either Pediatric, Pediatric Endocrine and/or Pediatric Surgery Outpatient

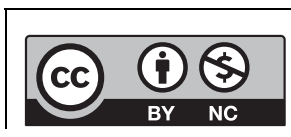

This work is licensed under a Creative Commons Attribution-NonCommercial 4.0 International License. 
Table 1 ICD-10 diagnoses included in the inquiry.

46,XY DSD
E34.5
Q53.2
Q54.2
Q54.3
Q55.00
Q55.01
Q56.1
Q97.3
46,XX DSD
Q52.0
Q52.1
Q56.2
Q98.3
E25.00
E25.01
Sex chromosome DSD
Q96.0-Q96.9
Q97.0-Q97.9
Q98.0.Q98.1
Q98.2,Q98.4
Q98.5-Q98.9
Unspecified DSD
E25.9
Q56.0
Q56.3
Q56.4
Other diagnoses
Q53.0
Q53.1
Q53.9
Q54.0
Q54.1
Q54.4
Q54.8
Q54.9
Q55.1
Q55.20
Q55.28
Q55.6
Q55.8
Q55.9
Q52.2
Q52.3
Q52.4
Q52.5
Q52.9

Androgen insensitivity syndrome

Undescended testicle, bilateral

Hypospadias, penoscrotal

Hypospadias, perineal

Absence and aplasia of testis

Anorchia

Male pseudohermaphroditism, not elsewhere classified

Female with $46, X Y$ karyotype

Congenital absence of vagina

Doubling of vagina

Female pseudohermaphroditism, not elsewhere classified

Other male with $46, \mathrm{XX}$ karyotype

Salt-losing congenital adrenal hyperplasia

Congenital adrenal hyperplasia

Turner syndrome and variants

Other sex chromosome abnormalities, female phenotype, not elsewhere classified

Klinefelter syndrome and variants

Other sex chromosome abnormalities, male phenotype, not elsewhere classified

Adrenogenital disorder, unspecified

Hermaphroditism, not elsewhere classified

Pseudohermaphroditism, unspecified

Indeterminate sex, unspecified

Ectopic testis

Undescended testicle, unilateral

Undescended testicle, unspecified

Hypospadias, balanic

Hypospadias, penile

Congenital chordee

Other hypospadias

Hypospadias, unspecified

Hypoplasia of testis and scrotum

Retractile testis

Unspecified congenital malformations of testis and scrotum

Other congenital malformations of penis

Other specified congenital malformations of male genital organs

Congenital malformation of male genital organ, unspecified

Congenital rectovaginal fistula

Imperforate hymen

Other congenital malformations of vagina

Fusion of labia

Other specified congenital malformations of female genitalia

Congenital malformation of female genitalia, unspecified

Exstrophy of urinary bladder

Persistent cloaca
Clinics at the Helsinki University Hospital between 2004 and 2014. Over two-thirds of these patients (72\%) had minor deviations of the genitourinary tract that are not classified as DSDs (Fig. 1 and Table 1). Patients with a DSD diagnosis $(n=550)$ were divided into three karyotypebased subgroups as suggested in the Chicago consensus statement (1); $53.3 \%$ had 46,XY DSD; $37.1 \%$ had sex chromosome DSD and 9.6\% had 46,XX DSD (Fig. 1).
Only $21 \%$ of 46 ,XX DSD patients and $7 \%$ of 46 ,XY DSD patients had a molecular genetic diagnosis, and none of those were made with next-generation sequencing methods. Even in patients with a distinct phenotype, such as persistent Müllerian duct syndrome, the diagnosis was seldom confirmed genetically. Age at diagnosis was available for $75 \%$ of $46, \mathrm{XY}$ DSD patients, $86 \%$ of $46, \mathrm{XX}$ DSD patients and $87 \%$ of sex chromosome DSD

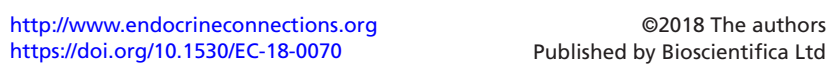




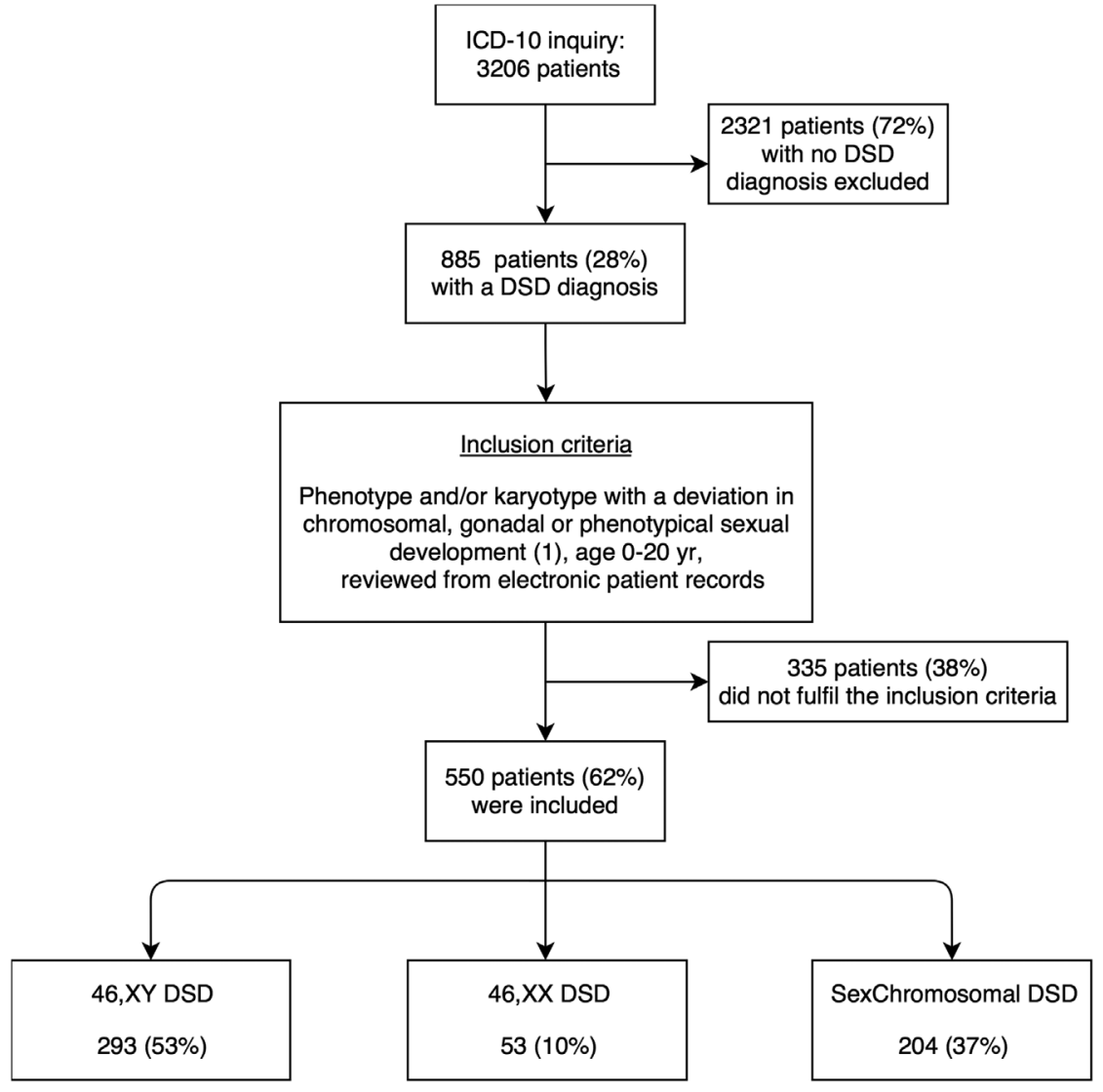

\section{Figure 1}

Inclusion criteria and outcomes. Patients retrieved from the ICD-10 inquiry $(n=3206)$ and DSD patients $(n=550)$ included in the analyses, divided into three subgroups based on 'Consensus statement on management of intersex disorders' (1). patients. Table 2 shows detailed distribution and timing of diagnoses among these DSD patients; most common diagnoses were bilateral cryptorchidism (23.1\%), TS $(19.8 \%)$ and KS (14.5\%). The mean age at diagnosis was $2.2 \pm 3.8$ years for $46, \mathrm{XY}$ DSD, $2.4 \pm 4.6$ years for $46, \mathrm{XX}$ DSD and $5.3 \pm 5.8$ years for sex chromosome DSD. In the majority of patients with $46, \mathrm{XY}$ DSD or $46, \mathrm{XX}$ DSD the diagnosis, based on phenotype or molecular genetic finding, was made immediately after birth, apart from 46,XX DSD patients expressing SRY and those presenting DSD as part of a syndrome.

Consanguinity was seldom reported in our data: only in two families, the parents were either first or second cousins. Two families with multiple DSD cases were identified. One family presented with several cases of persistent Müllerian duct syndrome. In the other family, there were two brothers with a DSD phenotype of unknown etiology (one brother had a micropenis with proximal hypospadias and a vaginal remnant and the other proximal hypospadias). In addition, three families where the DSD patient's sibling had a minor anatomic deviation were identified.

We next investigated the annual number of new DSD patients between 2004 and $2014(n=290)$, excluding patients who had been diagnosed before 2004 and had follow-up visits during the survey period. The annual number of new DSD patients remained stable (26 \pm 7 patients per year; mean \pm S.D., range $10-40)$ and did not correlate with time $(r=0.18, P=0.6, n=11)$. No significant trends in the annual number of patients were observed either when estimated separately in subgroups of 46,XY DSD (range 5-24, $r=0.31, P=0.4, n=11$ ), sex chromosome DSD (range 5-15, $r=-0.43, P=0.18, n=11$ ) and 46,XX DSD (range $0-6, r=-0.50, P=0.12, n=11$ ).

\section{Timing of diagnosis in sex chromosome DSDs: Turner syndrome and Klinefelter syndrome}

Our data allowed us to estimate the age at diagnosis of (TS) and (KS) (Fig. 2). For the 80 boys with KS, the diagnosis was set at the mean age of $6.8 \pm 6.2$ years mostly due to specific language impairment and/or learning difficulties (40\%), delayed motor development (13\%) or small testicles (11\%). Twelve boys were diagnosed already before birth (Fig. 2). Boys referred for evaluation due to developmental issues were aged $8.0 \pm 3.5$ years, and boys detected due to small testicular size $15.8 \pm 1.3$ years. Klinefelter boys diagnosed after birth were most frequently referred from 
Table 2 Classification of DSD patients $(n=550)$ by molecular diagnosis or phenotype, age at diagnosis and rate of molecular genetic diagnoses.

\begin{tabular}{|c|c|c|c|}
\hline & $\boldsymbol{n}(\%)$ & $\begin{array}{l}\text { Median (range) age } \\
\text { at diagnosis, years }\end{array}$ & $\begin{array}{l}\text { Molecular genetic } \\
\text { diagnosis (\%) }\end{array}$ \\
\hline \multicolumn{4}{|l|}{ 46,XY DSD } \\
\hline \multicolumn{4}{|l|}{ (A) Disorders of gonadal development } \\
\hline 1. Gonadal regression & $27(4.9)$ & $0.84(0.01-14.9)$ & 0 \\
\hline 2. Ovotesticular DSD & $2(0.4)$ & $7.9(0.04-15.7)$ & 0 \\
\hline \multicolumn{4}{|l|}{ (B) Disorders in androgen synthesis or action } \\
\hline 1. Androgen biosynthesis defect (3BHSD) & $1(0.2)$ & NA & 0 \\
\hline 2. Defect in androgen action (AIS) & $5(0.9)$ & $7.7(0-15.3)$ & 20 \\
\hline $\begin{array}{l}\text { 3. Disorders of AMH of AMH-receptor (persistent Müllerian } \\
\text { duct syndrome) }\end{array}$ & $7(1.3)$ & $0.7(0-2.4)$ & 29 \\
\hline \multicolumn{4}{|l|}{ (C) Other } \\
\hline \multicolumn{4}{|l|}{ 1. Unknown male undermasculinization } \\
\hline Bilateral cryptorchidism & $125(22.7)$ & $0.9(0-16.1)$ & 9 \\
\hline Severe hypospadias & $55(10.0)$ & $0.01(0-1.7)$ & 0 \\
\hline Severe hypospadias and bilateral cryptorchidism & $16(2.9)$ & $0.02(0-0.04)$ & 0 \\
\hline Micropenis & $5(0.9)$ & $0.01(0-10.6)$ & 0 \\
\hline Micropenis and bilateral cryptorchidism & $6(1.1)$ & $0.1(0-10.5)$ & 20 \\
\hline Micropenis and severe hypospadias & $8(1.5)$ & $0.01(0-0.4)$ & 0 \\
\hline Micropenis, bilateral cryptorchidism and severe hypospadias & $4(0.7)$ & $0(0-0.1)$ & 0 \\
\hline 2. Part of a syndrome (e.g. Prune Belly, Prader-Willi, Noonan) & 19 (3.5) & $0.02(0-11.5)$ & 42 \\
\hline 3. Cloacal extrophy & $13(2.4)$ & 0.0 & 0 \\
\hline \multicolumn{4}{|l|}{$46, X X$ DSD } \\
\hline \multicolumn{4}{|l|}{ (A) Disorders of gonadal development } \\
\hline 1. Ovotesticular DSD & $1(0.2)$ & 0.0 & 0 \\
\hline 2. SRY + & $4(0.7)$ & $6.3(0.3-18.1)$ & 100 \\
\hline \multicolumn{4}{|l|}{ (B) Androgen excess } \\
\hline 1. $\mathrm{CAH}$ & $31(5.6)$ & $0.0(0-8.8)$ & 23 \\
\hline \multicolumn{4}{|l|}{ (C) Other } \\
\hline $\begin{array}{l}\text { 1. Congenital structural abnormalities (e.g. vagina duplex, } \\
\text { vaginal atresia, clitoris hyperplasia) }\end{array}$ & $5(0.9)$ & $0.05(0-10.6)$ & 0 \\
\hline 2. Part of a syndrome (e.g. MRKH, HFGS) & $6(1.1)$ & $6.4(0-15.4)$ & 0 \\
\hline 3. Cloacal extrophy & $6(1.1)$ & 0.0 & 0 \\
\hline \multicolumn{4}{|l|}{ Sex chromosome DSD } \\
\hline (A) Turner syndrome and variants & $109(19.8)$ & $2.1(0-17.0)$ & \\
\hline (B) Klinefelter syndrome and variants & $80(14.5)$ & $6.7(0-17.4)$ & \\
\hline \multicolumn{3}{|l|}{ (D) Other } & \\
\hline Structural anomaly of $Y$ chromosome and testis retention & $1(0.2)$ & 0.07 & \\
\hline
\end{tabular}

the local healthcare center (24\%), maternity hospital (9\%) or department of pediatric neurology $(9 \%)$.

The girls with TS $(n=109)$ were diagnosed at the mean age of $4.7 \pm 5.5$ years. The age distribution was skewed as twenty-five girls were diagnosed prenatally, and, in $47 \%$ of the cases, diagnosis was reached by the age of one year (Fig. 2). Turner girls diagnosed after birth were most frequently referred by child health care clinic (19\%), maternity hospital (16\%) or another hospital district $(6 \%)$. The main complaint $(41 \%$ of all cases) was delayed growth. There were no significant trends in the age at diagnosis in either KS or TS patient groups between 2004 and 2014 (KS range 0-17 year, $r=0.05, P=0.75, n=44$; TS range $0-17$ year, $r=0.003$, $P=0.98, n=56)$.

\section{Timing of management in bilateral cryptorchidism}

Finally, we reviewed the changes in the management of cryptorchidism by estimating the age at operation for bilateral cryptorchidism before (years 2004-2007) and following the release of the Nordic consensus (years 2008-2014) on treatment of undescended testes (8). Altogether, during the whole study period (2004-2014), 142 patients were operated and the average age of operation for bilateral cryptorchidism was $45.1 \pm 44.8$ months. The annual number of operated patients (range 8-17) did not increase significantly during the survey period $(R=0.41, P=0.21, n=11)$. However, the age at operation declined after the release of the consensus from $54.5 \pm 43.0$ months to $41.1 \pm 45.3$ months $(P=0.0001)$. http://www.endocrineconnections.org https://doi.org/10.1530/EC-18-0070
C2018 The authors Published by Bioscientifica Ltd
This work is licensed under a Creative Commons Attribution-NonCommercial 4.0 International License. 


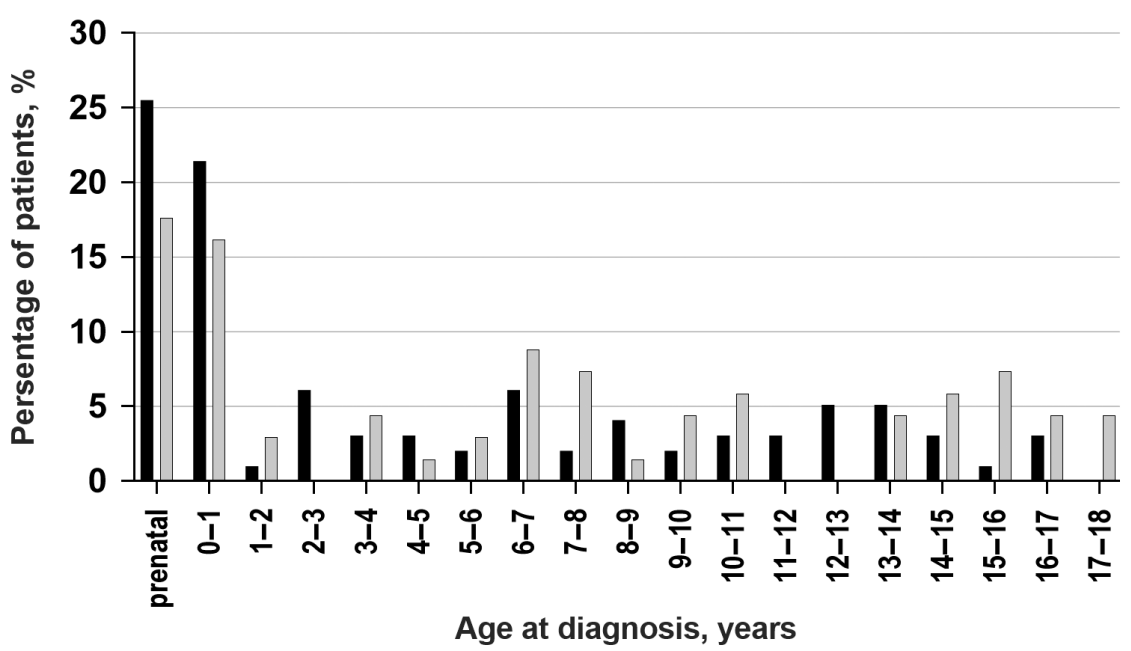

Figure 2

Percentage of TS $(n=98)$ and KS $(n=68)$ patients diagnosed per age group. Data obtained from patients visiting the outpatient clinics of a single tertiary center between 2004 and 2014 whose age at diagnosis was available.
Indeed, before the Nordic consensus statement, all bilateral cases $(n=42)$ were operated after the age of 1 year but after 2007, almost one-third (28 of 100 boys) was operated before the age of 1 year $(P=0.0001$, Fig. 3$)$. To exclude boys with acquired cryptorchidism and cases of congenital cryptorchidism missed in early childhood, we limited the analysis to those boys operated before the age of three (23). In this subanalysis, the age at operation had declined from $24.5 \pm 5.4$ months in boys operated between 2004 and 2007 to $13.7 \pm 5.3$ months in those operated after $2007(P<0.0001)$.

\section{Discussion}

Attempts to estimate the etiological distribution of DSDs according to the 2006-launched DSD classification system are few. In our series, approximately half of the patients had 46,XY DSD, whereas only one-tenth (9.6\%) had 46,XX DSD. The proportion of $46, \mathrm{XY}$ DSD patients is similar to the results reported from Turkey (47\%) (12), South Africa (57\%) (13) and North India (52.5\%) (17), and somewhat lower than has been reported from Indonesia (68\%) (16). On the other hand, our series contained more cases with sex chromosome DSDs than the previously mentioned reports, which may reflect differences in prenatal screening policies. Of note, in a recent Danish nationwide study, the estimated prevalence of androgen insensitivity syndrome was 2.3 per 100,000 live born females (24), which appears close to our frequency estimate based on the current catchment area of our tertiary center. In our study, congenital adrenal hyperplasia (CAH) was expectedly the most common cause of 46,XX DSD. After the implementation of the newborn screening in Finland

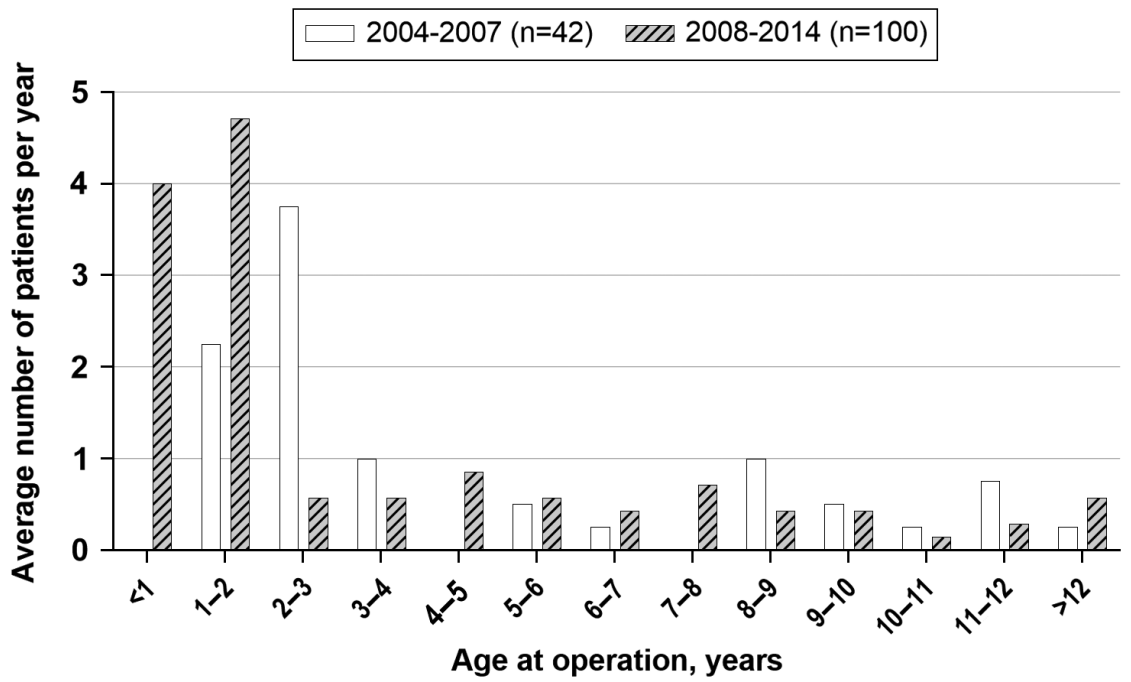

Figure 3

Age at orchiopexy. Age at bilateral orchiopexy or first of the two unilateral orchiopexies in a single tertiary center in 142 boys operated between 2004 and 2014. 42 boys were operated between 2004 and 2007 before the release of the Nordic consensus on treatment of undescended testes (8) and 100 boys thereafter.

$$
\begin{array}{lr}
\text { http://www.endocrineconnections.org } & \text { O2018 The authors } \\
\text { https://doi.org/10.1530/EC-18-0070 } & \text { Published by Bioscientifica Ltd }
\end{array}
$$


in 2015, six new CAH patients have been diagnosed by it. We anticipate that screening leads to better diagnostic yield and conceivably better care for this patient group in the future.

Since early diagnosis of DSD is considered important $(7,25,26)$, the efficacy of the diagnostic procedures of most frequent patient groups merits evaluation. The mean age at diagnosis of TS patients in our series was 4.7 years, a result similar to the findings reported from the United States and Spain $(26,27)$. A quarter of our TS patients was diagnosed prenatally, based on the voluntary, combined first trimester screening (a nuchal translucency scan and maternal serum screening followed by a prenatal chromosome test, if necessary). After birth, the most frequent symptom guiding to diagnosis was short stature (41\%), the leading clinical cue also in other studies (26, $27)$. The diagnosis of KS patients in our series was even further delayed, and the diagnosis was typically suspected during childhood due to developmental problems, and during adolescence due to small testicular size. If the frequency of KS was 1/667 male births in our area (28), we could roughly estimate that, between 2004 and 2006, $\sim 20-30 \%$ of the boys with KS were diagnosed before the age of 8 years. This low diagnostic yield is in agreement with the Danish data suggesting that only 10\% of Danish KS patients are diagnosed before the age of 14 years (29). One possibility to expedite diagnostics would be to include sex chromosome abnormalities in the national newborn screening programs, an idea that has been welltaken by parents of KS patients and pediatricians $(10,30)$. Also peer groups of TS (e.g. Turner Syndrome Society of the United States) are in favor of diagnosing TS as early as possible in order to anticipate the possible need of services required for variable defects in childhood (31). On the other hand, many pregnancies, in which TS is prenatally diagnosed, are currently terminated, although the severity of the TS phenotype is hard to predict and a postnatal re-evaluation of chromosomes is needed for an accurate diagnosis $(9,31)$.

The timing of orchiopexy is highly variable, and for example, $95 \%$ of surgeries were performed after the first year of life in German hospitals (32), and in Singapore, the corresponding number was 70\% (33). Nordic guidelines for the treatment of cryptorchidism were renewed at 2007 and accordingly the age for orchiopexy was advanced to 6-12 months (8). We tested whether implementation of the guideline in our tertiary center functions as an indicator for standard of care. Between 2004 and 2007, before the release of the Nordic consensus statement (8), not a single boy with bilateral cryptorchidism was operated before the age of one year in our hospital, whereas thereafter, the age at orchiopexy has decreased at least by 10 months. Our finding is in line with the results published from Sweden and Norway $(34,35)$.

In this cohort, $21 \%$ of patients with $46, \mathrm{XX}$ DSD and only $7 \%$ of $46, X Y$ DSD were diagnosed genetically. In the largest patient group of $46, \mathrm{XX}$ DSD, CAH, the current standard of diagnostics is still based on steroid hormone and other biochemical analyses instead of molecular genetics (36). For 46,XY DSD boys, it seems that the etiology remains largely unknown in the clinical setting. In the research setting, however, the overall genetic diagnostic rate achieved with a targeted DSD gene panel, can increase up to $43 \%$ (37). An accurate molecular genetic diagnosis is probably valuable in planning the long-term treatment of the patient, although more research is needed to show if the ever more precise diagnostics is associated with beneficial changes in clinical practice from the patient's perspective (38). While awaiting such evidence, it is still reasonable to conclude that the molecular genetic diagnostic rate should be improved by applying NGS methodology.

Our retrospective study has certain limitations. The ICD-10 classification has multiple different diagnosis codes describing the same phenomenon. To overcome this, we evaluated the patient records and chose the diagnostic code, which best described the patient's phenotype. Moreover, often there are no specific ICD-10 codes reserved for rare genetic diseases.

\section{Conclusions}

We present data from one of the largest series of DSD patients to date. Analysis of patients with chromosomal DSD shows that patients with TS or KS are diagnosed relatively late and often the initiative for the diagnostic workup is related to special needs of the patients (KS) or deceleration of growth (TS). It is feasible that age at diagnosis in patients with TS or KS and the age at operation of bilateral cryptorchidism could serve as indices for monitoring the diagnostic efficiency and management of DSD patients within and between different tertiary centers providing care for this vulnerable patient group.

\section{Declaration of interest}

The authors declare that there is no conflict of interest that could be perceived as prejudicing the impartiality of the research reported.

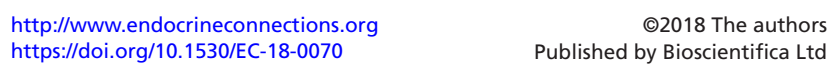




\section{Funding}

This work was supported by the Finnish foundation for Pediatric Research, Academy of Finland and Emil Aaltonen foundation.

\section{Author contribution statement}

All authors have provided substantial input to the concept of the study and drafting the article. E K, P M and T R designed the study. E K and A T collected the data. P M, S T, M H and T R advised in interpreting the patient data. E K analyzed the data and wrote the first draft of the manuscript. All authors contributed in revising and editing the manuscript.

\section{Acknowledgements}

The authors acknowledge Prof. Jorma Toppari, MD, PhD, for reading and commenting the manuscript.

\section{References}

1 Hughes IA, Houk C, Ahmed SF \& Lee PA. Consensus statement on management of intersex disorders. Journal of Pediatric Urology 20062 148-162. (https://doi.org/10.1016/j.jpurol.2006.03.004)

2 Hutson JM, Grover SR, O'Connell M \& Pennell SD. Malformation syndromes associated with disorders of sex development. Nature Reviews Endocrinology 201410 476-487. (https://doi.org/10.1038/ nrendo.2014.83)

3 Bonde JP, Flachs EM, Rimborg S, Glazer CH, Giwercman A, RamlauHansen CH, Hougaard KS, Høyer BB, Hærvig KK, Petersen SB, et al. The epidemiologic evidence linking prenatal and postnatal exposure to endocrine disrupting chemicals with male reproductive disorders: a systematic review and meta-analysis. Human Reproduction Update 201623 104-125. (https://doi.org/10.1093/humupd/dmw036)

4 Ahmed SF, Achermann JC, Arlt W, Balen A, Conway G, Edwards Z, Elford S, Hughes IA, Izatt L, Krone N, et al. Society for Endocrinology UK guidance on the initial evaluation of an infant or an adolescent with a suspected disorder of sex development (Revised 2015). Clinical Endocrinology 201584 771-788. (https://doi.org/10.1111/cen.12857)

5 Nordenström A, Röhle R, Thyen U, Bouvattier C, SlowikowskaHilczer J, Reisch N, et al. Hormone therapy and patient satisfaction with treatment, in a large cohort of diverse disorders of sex development. Clinical Endocrinology $2018 \mathbf{8 8} 397-408$. (https://doi. org/10.1111/cen.13518)

6 Quinton R, Mamoojee Y, Jayasena CN, Young J, Howard S, Dunkel L, Cheetham T, Smith N \& Dwyer AA. Society for Endocrinology UK guidance on the evaluation of suspected disorders of sexual development: emphasising the opportunity to predict adolescent pubertal-failure through a neonatal diagnosis of absent mini-puberty. Clinical Endocrinology 201686 305-306. (https://doi.org/10.1111/ cen.13257)

7 Cassia Amaral R, Inacio M, Brito VN, Bachega TASS, Oliveira AA, Domenice S, Denes FT, Sircili MH, Arnhold IJ, Madureira G, et al. Quality of life in a large cohort of adult Brazilian patients with 46,XX and $46, \mathrm{XY}$ disorders of sex development from a single tertiary centre. Clinical Endocrinology 201582 274-279. (https://doi.org/10.1111/ cen.12572)

8 Ritzén EM, Bergh A, Bjerknes R, Christiansen P, Cortes D, Haugen SE, Jörgensen N, Kollin C, Lindahl S, Läckgren G, et al. Nordic consensus on treatment of undescended testes. Acta Paediatrica 200796 638-643. (https://doi.org /10.1111/j.1651-2227.2006.00159.x)

9 Bondy CA \& Turner Syndrome Study Group. Care of girls and women with Turner syndrome: a guideline of the Turner Syndrome Study Group. Journal of Clinical Endocrinology and Metabolism 200792 10-25. (https://doi.org/10.1210/jc.2006-1374)
10 Gies I, Tournaye H \& De Schepper J. Attitudes of parents of Klinefelter boys and pediatricians towards neonatal screening and fertility preservation techniques in Klinefelter syndrome. European Journal of Pediatrics 2016175 399-404. (https://doi.org/10.1007/ s00431-015-2657-7)

11 Lux A, Kropf S, Kleinemeier E, Jürgensen M, Thyen U \& DSD Network Working Group. Clinical evaluation study of the German network of disorders of sex development (DSD)/intersexuality: study design, description of the study population, and data quality. BMC Public Health 20099 110. (https://doi.org/10.1186/1471-24589-110)

12 Erdoğan S, Kara C, Uçaktürk A \& Aydın M. Etiological classification and clinical assessment of children and adolescents with disorders of sex development. Journal of Clinical Research in Pediatric Endocrinology 20113 77-83. (http://doi.org/10.4274/jcrpe.v3i2.16)

13 Ganie Y, Aldous C, Balakrishna Y \& Wiersma R. Disorders of sex development in children in KwaZulu-Natal Durban South Africa: 20-year experience in a tertiary centre. Journal of Pediatric Endocrinology and Metabolism 201630 11-18. (https://doi. org/10.1515/jpem-2016-0152)

14 Jaruratanasirikul S \& Engchaun V. Management of children with disorders of sex development: 20-year experience in southern Thailand. World Journal of Pediatrics 201410 168-174. (https://doi. org/10.1007/s12519-013-0418-0)

15 Al-Jurayyan NAM. Ambiguous genitalia: two decades of experience. Annals of Saudi Medicine 201131 284-288. (https://doi. org/10.4103/0256-4947.81544)

16 Juniarto AZ, van der Zwan YG, Santosa A, Ariani MD, Eggers S, Hersmus R, Themmen AP, Bruggenwirth HT, Wolffenbuttel KP, Sinclair A, et al. Hormonal evaluation in relation to phenotype and genotype in 286 patients with a disorder of sex development from Indonesia. Clinical Endocrinology 201685 247-257. (https://doi. org/10.1111/cen.13051)

17 Walia R, Singla M, Vaiphei K, Kumar S \& Bhansali A. Disorders of sex development: a study of 194 cases. Endocrine Connections 20187 364-371. (https://doi.org/10.1530/EC-18-0022)

18 Hiort O, Wünsch L, Cools M, Looijenga L \& Cuckow P. Requirements for a multicentric multidisciplinary registry on patients with disorders of sex development. Journal of Pediatric Urology 20128 624-628. (https://doi.org/10.1016/j. jpurol.2012.09.004)

19 Pasterski V, Prentice P \& Hughes IA. Consequences of the Chicago consensus on disorders of sex development (DSD): current practices in Europe. Archives of Disease in Childhood 201095 618-623. (https:// doi.org/10.1136/adc.2009.163840)

20 Creighton S, Chernausek SD, Romao R, Ransley P \& Salle JP. Timing and nature of reconstructive surgery for disorders of sex development - introduction. Journal of Pediatric Urology 20128 602-610. (https:// doi.org/10.1016/j.jpurol.2012.10.001)

21 Official Statistics of Finland. Population: Population structure. Helsinki, Finland: Statistics Finland, 2017. (available at: http://www. stat.fi/til/vaerak/index_en.html)

22 Bonomi M, Rochira V, Pasquali D, Balercia G, Jannini EA \& Ferlin A. Klinefelter syndrome (KS): genetics, clinical phenotype and hypogonadism. Journal of Endocrinological Investigation 201640 123-134. (https://doi.org/10.1007/s40618-016-0541-6)

23 Wohlfahrt-Veje C, Boisen KA, Boas M, Damgaard IN, Kai CM, Schmidt IM, Chellakooty M, Suomi AM, Toppari J, Skakkebaek NE, et al. Acquired cryptorchidism is frequent in infancy and childhood. International Journal of Andrology 200932 423-428. (https://doi. org/10.1111/j.1365-2605.2008.00946.x)

24 Berglund A, Johannsen TH, Stochholm K, Viuff MH, Fedder J, Main KM \& Gravholt $\mathrm{CH}$. Incidence, prevalence, diagnostic delay, and clinical presentation of female 46,XY disorders of sex development. Journal of Clinical Endocrinology and Metabolism 2016 101 4532-4540. (https://doi.org/10.1210/jc.2016-2248)

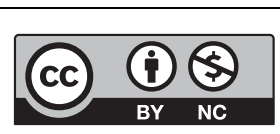

This work is licensed under a Creative Commons Attribution-NonCommercial 4.0 International License. 
25 Hersmus R, Stoop H, White SJ, Drop SLS, Oosterhuis JW, Incrocci L, Wolffenbuttel KP \& Looijenga LHJ. Delayed recognition of disorders of sex development (DSD): a missed opportunity for early diagnosis of malignant germ cell tumors. International Journal of Endocrinology 20122012671209.

26 Sävendahl L \& Davenport ML. Delayed diagnoses of Turner's syndrome: proposed guidelines for change. Journal of Pediatrics 2000 137 455-459. (https://doi.org/10.1067/mpd.2000.107390)

27 Ríos Orbañanos I, Vela Desojo A, Martinez-Indart L, Grau Bolado G, Rodriguez Estevez A \& Rica Echevarria I. Turner syndrome: from birth to adulthood. Endocrinología y Nutrición 201562 499-506. (https://doi.org/10.1016/j.endonu.2015.06.010)

28 Bojesen A, Juul S \& Gravholt CH. Prenatal and postnatal prevalence of Klinefelter syndrome: a national registry study. Journal of Clinical Endocrinology and Metabolism 200388 622-626. (https://doi. org/10.1210/jc.2002-021491)

29 Groth KA, Skakkebæk A, Høst C, Gravholt CH \& Bojesen A. Clinical review: Klinefelter syndrome - a clinical update. Journal of Clinical Endocrinology and Metabolism 201398 20-30. (https://doi. org/10.1210/jc.2012-2382)

30 Herlihy AS \& McLachlan RI. Screening for Klinefelter syndrome. Current Opinion in Endocrinology, Diabetes and Obesity 201522 224-229. (https://doi.org/10.1097/MED.0000000000000154)

31 Baena N, De Vigan C, Cariati E, Clementi M, Stoll C, Caballín MR \& Guitart M. Turner syndrome: evaluation of prenatal diagnosis in 19 European registries. American Journal of Medical Genetics Part A 2004 129A 16-20. (https://doi.org/10.1002/ajmg.a.30092)

32 Hensel KO, Caspers T, Jenke AC, Schuler E \& Wirth S. Operative management of cryptorchidism: guidelines and reality - a 10-year observational analysis of 3587 cases. BMC Pediatrics 201515116. (https://doi.org/10.1186/s12887-015-0429-1)

33 Nah SA, Yeo CSW, How GY, Allen JC, Lakshmi NK, Yap T-L, Jacobsen AS, Low Y \& Ong CC. Undescended testis: 513 patients' characteristics, age at orchidopexy and patterns of referral. Archives of Disease in Childhood 201499 401-406. (https://doi.org/10.1136/ archdischild-2013-305225)

34 Bergbrant S, Omling E, Björk J \& Hagander L. Cryptorchidism in Sweden: a nationwide study of prevalence, operative management, and complications. Journal of Pediatrics 2018194 197-203.e6. (https://doi.org/10.1016/j.jpeds.2017.09.062)

35 Nilsson R, Omland H, Dahl AA \& Johansen TEB. Early outcome of orchiopexy and analysis of predictive factors: a retrospective study from 2001 to 2010 in a Norwegian regional hospital. Scandinavian Journal of Urology 201448 474-481. (https://doi.org/10.3109/216818 05.2014.905631)

36 Kulle A, Krone N, Holterhus PM, Schuler G, Greaves RF, Juul A, de Rijke YB, Hartmann MF, Saba A, Hiort O, et al. Steroid hormone analysis in diagnosis and treatment of DSD: position paper of EU COST Action BM 1303 'DSDnet'. European Journal of Endocrinology 2017176 P1-P9. (https://doi.org/10.1530/EJE-16-0953)

37 Eggers S, Sadedin S, van den Bergen JA, Robevska G, Ohnesorg T, Hewitt J, Lambeth L, Bouty A, Knarston IM, Tan TY, et al. Disorders of sex development: insights from targeted gene sequencing of a large international patient cohort. Genome Biology 201617243. (https://doi.org/10.1186/s13059-016-1105-y)

38 Alhomaidah D, McGowan R \& Ahmed SF. The current state of diagnostic genetics for conditions affecting sex development. Clinical Genetics 201791 157-162. (https://doi.org/10.1111/cge.12912)

Received in final form 15 March 2018

Accepted 26 March 2018

Accepted Preprint published online 26 March 2018 http://www.endocrineconnections.org https://doi.org/10.1530/EC-18-0070
@2018 The authors Published by Bioscientifica Ltd

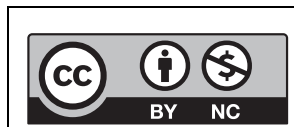

This work is licensed under a Creative Commons Attribution-NonCommercial 4.0 International License. 